\section{Advising on diet and lifestyle: naturopathy's role?}

I read with interest the research article in $C M A J$ by Seely and colleagues ${ }^{1}$ regarding the reduction of calculated coronary heart disease risk. The goal of their investigation was to test the hypothesis that naturopathic care is superior to usual care. Although the authors have shown that a generous investment in counselling is effective at reducing calculated risk of coronary heart disease, they have not shown any effect specifically attributable to naturopathic care. For example, dietary counselling appears to be effective regardless of the provider. ${ }^{2}$ As a practising cardiologist, I routinely "deliver diet and health promotion advice" to my patients and "emphasize this form of self-directed care." In response to a statement in the accompanying CMAJ editorial by Stanbrook, ${ }^{3}$ I would welcome the opportunity to spend an additional 4 hours in consultation with my patients who are at high risk for coronary heart disease, and I suggest such an intervention would have been the appropriate control comparator.

Furthermore, I have concern about the evidence base used to determine lifestyle interventions. Appendix 1 in the article by Seely and colleagues ${ }^{1}$ suggests that coffee intake should be reduced or eliminated. Literature published before the trial registration, however, showed an association between moderate coffee intake and both a reduced risk of diabetes $^{4}$ and no increase in risk of coronary heart disease. ${ }^{5}$ Conversely, the evidence showed little clinical benefit from some of the recommended supplements, or showed no evidence that supports a clinical benefit (i.e., from cinnamon, pomegranate juice, lutein).

\section{David E. Winchester MD MS}

Assistant professor, Division of Cardiovascular Medicine, University of Florida, Gainesville, Fla.

\section{References}

1. Seely D, Szczurko O, Cooley K, et al. Naturopathic medicine for the prevention of cardiovascular disease: a randomized clinical trial. CMAJ 2013;185:E409-16.

2. Rees K, Dyakova M, Ward K, et al. Dietary advice for reducing cardiovascular risk. Cochrane Database Syst Rev 2013;(3):CD002128.

3. Stanbrook MB. Can naturopaths deliver complementary preventive medicine? CMAJ 2013; 185:747

4. van Dam RM, Hu FB. Coffee consumption and risk of type 2 diabetes: a systematic review. JAMA 2005;294:97-104.

5. Lopez-Garcia E, van Dam RM, Willett WC, et al. Coffee consumption and coronary heart disease in men and women: a prospective cohort study. Circulation 2006;113:2045-53.

\section{CMAJ 2013. DOI:10.1503/cmaj.113-2141}

CMAJ is to be commended for its openness in publishing research on alternative medicine, provided the studies are appropriately designed and discussed, which is the case with the article by Seely and colleagues. ${ }^{1}$

Our comment on the CMAJ editorial by Stanbrook $^{2}$ is that naturopaths are not formal members of health teams that provide nutrition guidance; this is the role of dietitians. That physicians usually partner with dietitians, whether in the hospital or community setting, seems to have been totally overlooked in Stanbrook's ${ }^{2}$ editorial. Similar results could have been achieved had dietitians provided preventive eating and lifestyle guidance.

Naturopaths can certainly provide evidence-based dietary advice, as shown in Seely and colleagues" ${ }^{1}$ intervention in their study. However, naturopaths also tend to be heavy prescribers of natural health products, as evidenced by the 7 food supplements listed in the menu of interventions in the study. Such supplements may be unnecessary and evidence of their efficacy is limited.

Referring to naturopathic practice as "complementary preventive medicine"1 increases the confusion between naturopathy and dietetics. One wonders what the rationale is for delegating diet and lifestyle advice to naturopaths when there are dietitians to provide advice regarding healthy eating.

\section{Hélène Delisle RD PhD, Sarah Lefebvre RD MSc}

Department of Nutrition (Delisle); student, nutrition (Lefebvre), University of Montréal, Montréal, Que.

\section{References}

1. Seely D, Szczurko O, Cooley K, et al. Naturopathic medicine for the prevention of cardiovascular disease: a randomized clinical trial. CMAJ 2013; 185:E409-16.

2. Stanbrook MB. Can naturopaths deliver complementary preventive medicine? CMAJ 2013;185:747.

CMAJ 2013. DOI:10.1503/cmaj.113-2142

I would like to congratulate $C M A J$ on publishing articles pertaining to complementary and alternative medicine. ${ }^{1,2}$ This is a step in the right direction. I am a naturopathic doctor, and my husband is a family physician and an emergency physician. We have seen first-hand how great things can happen for patients when medical professionals from all aspects of health care work together.

The level of discontent with our current health care model is growing among patients and health care workers. It is time for great minds from all areas of medicine to work together toward a common goal of better serving the needs of patients. Naturopathic doctors are in a unique position to support the conventional model of health care, and we have the time and training required to address lifestyle and preventative strategies with patients. The articles in $C M A J^{1,2}$ stress the importance of research to validate many of the therapies used by naturopaths - and I agree that this is very important. But let us not forget that many conventional medical practices are not supported by scientific research either and yet they are accepted as valid therapies and rarely questioned.

We need to join forces, open the lines of communication, share our expertise and show patients a unified front so they can feel supported in their health care goals. As Scottish legend Thomas Dewar once said, "Minds are like parachutes; they only function when they are open."

\section{Jennifer Simpson BSc MSc ND}

Naturopathic doctor, Core Health Naturopathic Wellness Centre, Muskoka and Parry Sound, Ont.

\section{References}

1. Seely D, Szczurko O, Cooley K, et al. Naturopathic medicine for the prevention of cardiovascular disease: a randomized clinical trial. CMAJ 2013; 185:E409-16.

2. Stanbrook MB. Can naturopaths deliver complementary preventive medicine? CMAJ 2013;185:747.

CMAJ 2013. DOI:10.1503/cmaj.113-2143 